\title{
Corrigendum
}

\section{A Randomized, Placebo-Controlled, Active-Reference, Double-Blind, Flexible-Dose Study of the Efficacy of Vortioxetine on Cognitive Function in Major Depressive Disorder}

\author{
\begin{tabular}{|c|}
\hline Atul R Mahableshwarkar, John Zajecka, William Jacobson, Yinzhong Chen and Richard SE Keefe \\
\hline Neuropsychopharmacology (2016) 41, 2961. doi:10.1038/npp.2016.181
\end{tabular}
}

Correction to: Neuropsychopharmacology (2015) 40, 2025-2037; doi:10.1038/npp.2015.52; published online 1 April 2015

Following publication, the authors reported the following errors in Figure 2, Table 2, and Supplementary Appendixes A-C. These small errors do not change the content, statistics, or conclusions of the report.

Page 2030: In Figure 2, the label below the $x$ axis should say that the mean DSST score was 43.1, not 42 .

Page 2031, Table 2:

In the top row ('DSST-number of correct symbols'), the upper CI limit for duloxetine is incorrect. The entry should read ' $1.21 \pm 0.73(-0.23 ; 2.65)$ ', not ' $1.21 \pm 0.73(-0.23 ; 2.56)$ '.

Under 'Secondary end points assessing cognitive dysfunction,' in the row 'Identification task,' the difference from placebo for vortioxetine should be -0.01 , not -0.02 .

Under 'Additional endpoints', in the row 'WLQ-Percentage Productivity Loss', the change from baseline for placebo should be $-3.07 \pm 0.65$, not $3.07 \pm 0.65$. In the row 'WLQ-Time Management', the change from baseline for placebo should be $-12.78 \pm 3.02$, not $-3.07 \pm 0.65$.

Supplementary Appendix A online: The screening period was from Day -10 to Day -2, not Day -14 to Day -7.

Supplementary Appendix B online: Under 'Additional Endpoints', in the fourth item, the name of the university and the description of the measure are incorrect. The entry should be 'Change from baseline to week 8 in the University of
California San Diego Performance-Based Skills Assessment (UPSA) (performance-based measure of functional capacity)', not 'Change from baseline to week 8 in the University of San Diego Performance-Based Skills Assessment (UPSA) (performance measures of functional capacity)'.

Supplementary Appendix C online: Some asterisks were difficult to interpret, and the $n$ value for duloxetine at 4 weeks was incorrect. Please see the corrected graph accompanying the corrigendum, below and online.

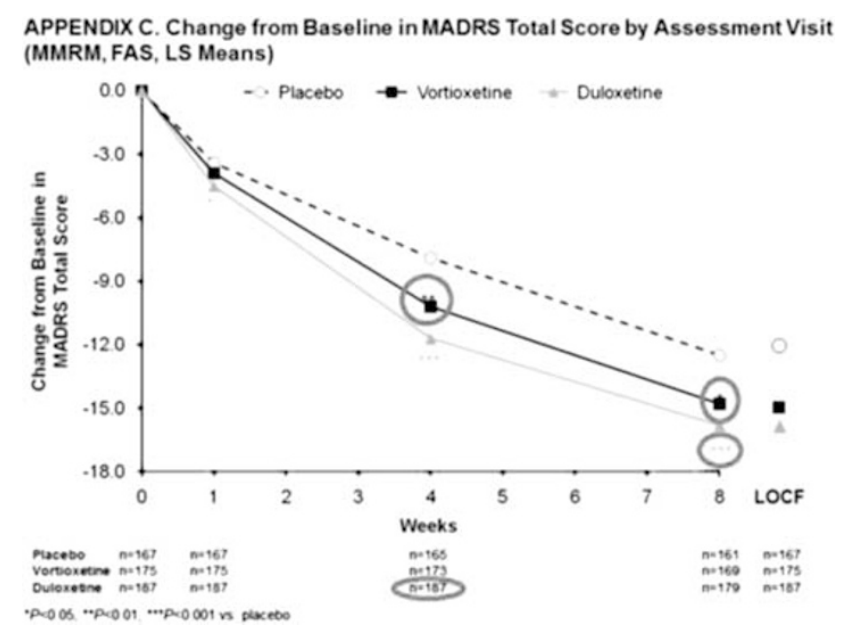

Supplementary Information accompanies the paper on the Neuropsychopharmacology website (http://www.nature.com/npp) 